\section{Case Reports in Gastroenterology}

Case Rep Gastroenterol 2020;14:39-47

DOI: 10.1159/000504645

Published online: January 22, 2020
(C) 2020 The Author(s)

Published by S. Karger AG, Basel www.karger.com/crg

This article is licensed under the Creative Commons Attribution-NonCommercial 4.0 International License (CC BY-NC) (http://www.karger.com/Services/OpenAccessLicense). Usage and distribution for commercial purposes requires written permission.

\title{
An Epileptic Patient with Recurrent Hyperbilirubinemia Caused by Gilbert Syndrome
}

\author{
Yaoyao Zhang Yongli Jiang Fang Yuan Changgeng Song \\ Zhihan Zhao Wen Jiang \\ Department of Neurology, Xijing Hospital, Fourth Military Medical University, \\ Xi'an, PR China
}

\section{Keywords}

Gilbert syndrome · Valproic acid · Lamotrigine $\cdot$ Hyperbilirubinemia · UGT1A1

\begin{abstract}
Gilbert syndrome (GS) is characterized by intermittent indirect bilirubin elevation. Several antiepileptic drugs (AEDs) impair the liver function to different degrees, such as valproic acid, lamotrigine, phenobarbital, phenytoin, and carbamazepine. Herein, we present the case of a 26-year-old epileptic patient with frequently recurring mild hyperbilirubinemia during taking AEDs. After repeated adjustment of the doses and types of AEDs, the bilirubin level still remained elevated. He was then referred to the Gastroenterology Department. The results of diagnostic tests, clinical manifestation, imaging studies, liver biopsy and whole-exome sequencing all made contributions to our conclusion that GS played an important role in the elevation of bilirubin. Ultimately, his seizure was controlled by levetiracetam (500 mg per day) and he was advised to periodically undergo the liver function tests.
\end{abstract}

(C) 2020 The Author(s)

Published by S. Karger AG, Basel 


\section{Case Reports in Gastroenterology}

\begin{tabular}{l|l} 
Case Rep Gastroenterol 2020;14:39-47 \\
\hline DOI: 10.1159/000504645 & $\begin{array}{l}\text { @ } 2020 \text { The Author(s). Published by S. Karger AG, Basel } \\
\text { www.karger.com/crg }\end{array}$
\end{tabular}

Zhang et al.: Gilbert Syndrome Concurrent with Epilepsy

\section{Introduction}

Gilbert syndrome (GS) is a benign and hereditary hyperbilirubinemia. It is characterized by intermittent indirect bilirubin elevation, which is attributed to the reduced activity of UDPglucuronosyltransferase 1A isoform 1 (UGT1A1) [1]. It has a prevalence of 3-10\% in the general population, and men are more vulnerable than women $[2,3]$. Epilepsy is one of the most common chronic neurological disorders. It is caused by heterogeneous etiologies, involving genetic, structural, infectious, metabolic, immune and other unknown factors, with an enduring predisposition to engender unprovoked epileptic seizures [4]. It needs continuous antiepileptic drug (AED) treatment. However, several AEDs would impair the liver function mildly or severely, such as valproic acid (VPA), lamotrigine (LTG), phenobarbital, phenytoin, and carbamazepine, the degree of hepatic injury ranging from mild hyperbilirubinemia to fulminant liver failure. Therefore, when a patient taking AEDs metabolized by hepatic pathways, if he manifested slight hyperbilirubinemia, how to differentiate it with GS needs further diagnostic workup.

We here report the case of a 26-year-old male who was diagnosed as having idiopathic generalized epilepsy (IGE) concurrent with GS. Our experience during the treatment of the patient cautions the clinicians that when an epileptic patient has repeated elevation of bilirubin, GS should also be considered while suspecting him of having drug-induced liver damage.

\section{Case Presentation}

A 26-year-old male who had been treated for paroxysmal convulsions for more than 9 years had a concurrent 9-year history of bilirubin elevation. In December 2009, when he was 16 years old, he suddenly presented with stiffness of the whole body without aura, with his arms and legs shaking and with loss of consciousness lasting for 2-3 min. Postictal symptoms included headache, being exhausted, inability to concentrate and sleepiness. However, the patient was not taken to the hospital for further medical attention.

In March 2010, the same unprovoked seizures as described above occurred twice within $5 \mathrm{~h}$ and every episode lasted for a few minutes, but he was awake between the two episodes of seizure. He sought treatment in a tertiary hospital and took a 24-h video electroencephalography (EEG) examination. The interictal 24 -h video EEG revealed, on a normal background, a spike-and-slow-wave complex on the right lateral frontal pole, frontal and central-frontal regions. The magnetic resonance imaging scan of the brain was normal and there was no history of familial epilepsy, structural trauma, infection, immune disorder, cerebrovascular disease, and febrile convulsion. Then he was diagnosed as having IGE and was prescribed extendedrelease VPA (Depakine, DPK) of $500 \mathrm{mg}$ per day. After having taken VPA for 3 months, his liver function tests showed abnormal alanine aminotransferase (60 U/L, normal: 9-50 U/L), aspartate aminotransferase (47 U/L, normal: $29-35 \mathrm{U} / \mathrm{L})$, total bilirubin $(73.5 \mu \mathrm{mol} / \mathrm{L}$, normal: 0-25 $\mu \mathrm{mol} / \mathrm{L})$, direct bilirubin $(21.2 \mu \mathrm{mol} / \mathrm{L}$, normal: $0-7 \mu \mathrm{mol} / \mathrm{L})$, and indirect bilirubin $(52.3$ $\mu \mathrm{mol} / \mathrm{L}$, normal: 0-18 $\mu \mathrm{mol} / \mathrm{L})$. Thus, he immediately discontinued taking DPK by himself because of these abnormal results.

Then, he was referred to Xijing hospital in July 2010. Taking hepatic injury probably induced by VPA into account, he was prescribed LTG. The dosage was based over 6 weeks and 


\section{Case Reports in Gastroenterology}

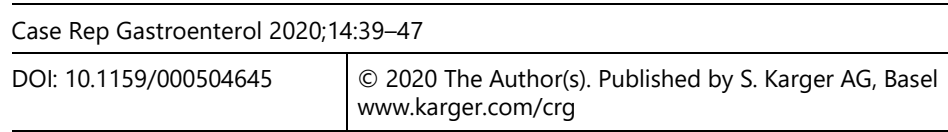
www.karger.com/crg

Zhang et al.: Gilbert Syndrome Concurrent with Epilepsy

increased from $25 \mathrm{mg}$ q.d. to $50 \mathrm{mg}$ b.i.d. However, during the 6 months of taking LTG, the patient's bilirubin level still remained elevated mildly and intermittently. Thus, we chose the alternative drug levetiracetam (LEV) as the most appropriate medicine, and its dosage was based over 2 weeks, increasing from $250 \mathrm{mg}$ b.i.d. to $250 \mathrm{mg}$ per morning, and $500 \mathrm{mg}$ per night while LTG was gradually withdrawn. In the meantime, he was advised to have a consultation at the Gastroenterology Department for hyperbilirubinemia.

In August 2011, an adjustment of the dosage of LEV was made to $500 \mathrm{mg}$ b.i.d. after another epileptic seizure occurred. In the meantime, he was admitted to the Gastroenterology Department at Xijing hospital for intermittently elevated bilirubin (total bilirubin 66.2 $\mu \mathrm{mol} / \mathrm{L}$, direct bilirubin $7.5 \mu \mathrm{mol} / \mathrm{L}$, indirect bilirubin $58.7 \mu \mathrm{mol} / \mathrm{L}$ ). He had no jaundice on his skin or mucosa. The serum tests for hepatitis A, B, and C were all negative, and his abdominal ultrasound was also normal. However, findings of diagnostic tests including caloric restriction, phenobarbital and oral phenytoin sodium stimulation were all positive (Table 1), which suggested the possibility of GS.

In order to exclude liver damage induced by VPA and/or LTG and confirm the diagnosis of GS, we took a liver biopsy. The pathological results showed that hepatocytes were mildly edematous and there were only few eosinophils infiltrating in them (Fig. 1). It was also recommended that the consideration of GS should rule out a recent history of using hepatotoxic drugs or substances. This means that the abnormal bilirubin level might have been induced by both VPA/LTG and GS. Therefore, to further identify GS, we took whole-exome sequencing (WES) of the patient. Genomic DNA was extracted from the patient using standard protocols. The amplified DNA of the proband was captured, using biotinylated oligo-probes. Paired-end sequencing was performed on a next-generation HiSeq2000 sequencer (Illumina, San Diego, CA, USA) with a depth of $\sim 200 X$. Raw image files were processed using Bcl2Fastq software (Bcl2Fastq 2.18.0.12, Illumina, Inc.) for base calling and raw data generation. Low-quality variations were filtered out using a quality score $\geq 20$. Illumina clean reads were aligned to the reference human genome (hg19) using BWA software package (version 0.7.15). Polymerase chain reaction duplicates were removed using the Picard program, and the deletions and insertions (InDels) were detected using the GATK software package (version 3.7.). The identified SNPs/inDels were annotated using the Exome-assistant program and were filtered if they showed up with $>5 \%$ frequency in several databases, such as dbSNP138, 1000 Genomes, and 1000 MyGenostics in-house Asia database. Nonsynonymous variants were evaluated according to the SIFT, PolyPhen and Mutation Taster. Finally, a homozygous mutation (p. A(TA)6TAA ins TA) in the UGT1A1 promoter of the GS pathogenic gene locus was found and there was no causative genetic mutation of epilepsy (Fig. 2). Combined with the above-mentioned tests and his history of nonhemolytic bilirubin metabolic disorder, the diagnosis of GS concurrent with IGE was clear.

In order to strike a balance between seizure control and reduction of the degree of liver damage, we suggest that he should continuously take LEV. He was subsequently discharged from the hospital and was advised to avoid hunger, fatigue as well as avoid taking VPA, LTG or some other drugs which were metabolized by hepatic glucuronidation. During the next 8 years, he remained seizure-free by taking LEV (500 mg per day). However, this was still concurrent with intermittent elevation of the bilirubin level. 


\section{Case Reports in Gastroenterology}

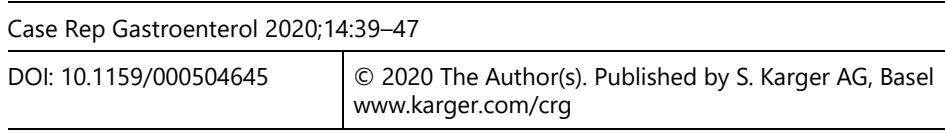
www.karger.com/crg

Zhang et al.: Gilbert Syndrome Concurrent with Epilepsy

The patient's EEG was reviewed in 2017 and no abnormal findings were detected. In March 2019, the patient stopped taking LEV for 17 months, and the results of the liver function tests at 1, 5, 10 and 17 months after discontinuation of LEV were still abnormal (Table 1).

\section{Discussion and Conclusion}

This case report, to our knowledge, is the first report of epilepsy concurrent with GS. Although there is no shared genetic and pathophysiological basis between epilepsy and GS, we still want to express our experiences during treating the patient. As we all know, epilepsy is a condition that needs continuous AED treatment. However, several AEDs can cause abnormality of liver function tests including an abnormal bilirubin level. Thus, when an epileptic patient presented with recurrent hyperbilirubinemia, is it just because of the side effects of AEDs?

GS is a benign condition and treatment is typically not necessary [5]. The pathogenesis of GS involves the reduced activity of UGT1A1 [2], a phase II drug metabolic enzyme, which is primarily capable of converting a series of insoluble drugs such as irinotecan and atazanavir to water-soluble substances, which are easy for the renal or biliary elimination and excretion $[6,7]$. In addition, it is also the isozyme that plays a significant role in bilirubin conjugation. The activity of UGT1A1 can be reduced by 70\% in GS [8], which results in intermittently and mildly elevated unconjugated bilirubin, mostly ranging from 20 to $50 \mu \mathrm{mol} / \mathrm{L}$ but rarely exceeding $70 \mu \mathrm{mol} / \mathrm{L}[9,10]$.

Currently, GS is usually based on diagnosis of exclusion; its prominent clinical manifestation is mild elevation of indirect bilirubin in serum, lacking other reasons of unconjugated hyperbilirubinemia [11]. Physical examination, biochemistry tests, imaging studies and liver histology (usually not necessary) are all normal in GS. Notably, genetic detection is playing an increasingly decisive role in differentiating GS from other hereditary conditions with hyperbilirubinemia such as Crigler-Najjar syndrome [2]. In our case, according to the patient's clinical manifestation, biochemistry of liver function, results of diagnostic tests, abdominal ultrasound, liver biopsy and WES, we can draw the conclusion that GS is primarily responsible for the elevated bilirubin.

VPA and LTG are the first-line drugs for focal and generalized seizures [12]. VPA has a wide range of metabolic pathways: $30-40 \%$ of the dose is via conjugation with UDP-glucuronyl transferases (UGT) such as UGT1A3 and UGT2B7 [13], and the pathway of mitochondrial beta oxidation accounts for $40 \%$. Other oxidative pathways such as omega and omega-1 are also implicated in it [14]. The enzyme UGT1A4 may be involved in the metabolism of LTG [15]. Therefore, VPA and LTG should be avoided because of their main metabolic pathways in the liver, though not involving the UGT1A1.

Clarkson and Choonara [16] and Su-Yin et al. [17] once reported that VPA/LTG can cause liver injury to different degrees. Hepatic injuries associated with these AEDs could be classified into two subtypes: the common type and the fulminant liver failure type. The former one shows temporary and reversible elevation of bilirubin in serum and the concentration of liver enzyme, which usually act in a dose-dependent manner and the abnormalities can return to normal shortly after discontinuing taking the drugs [18]. The latter one is characteristic of lifethreatening but is infrequent, generally occurring within 2-8 weeks (LTG) or 3 months (VPA) of taking these AEDs $[19,20]$. That might have caused interference before we identified the 


\section{Case Reports in Gastroenterology}

Case Rep Gastroenterol 2020;14:39-47

DOI: $10.1159 / 000504645$

(c) 2020 The Author(s). Published by S. Karger AG, Base www.karger.com/crg

Zhang et al.: Gilbert Syndrome Concurrent with Epilepsy

definite reason of the elevated bilirubin level. However, LEV is metabolized by enzymatic hydrolysis of the acetamide group in the blood rather than liver cytochrome P450 enzymes [21, 22]. Thus, it has a minor effect on the liver function. The combination of a minor influence on the liver and good seizure control in IGE make LEV a better choice for epilepsy concurrent with GS, though its efficacy in seizure control of IGE ranks only third to VPA and LTG [12].

In this case, at first, we did not withdraw LTG immediately, considering the fact that the harm caused by epileptic seizures was much more severe than the signs of slightly abnormal liver tests possibly induced by LTG [23]. However, after taking LTG for several weeks, the bilirubin still remained mildly abnormal. Then, LTG was replaced with LEV. LEV, as a new broadspectrum AED with relatively fewer side effects and fewer drug interactions, is increasingly used as adjunctive therapy to treat generalized epilepsy [24]. Moreover, it does not inhibit the activity of UGT1A1, and about $34 \%$ of its dose is metabolized via enzymatic hydrolysis of the acetamide group in blood and the remainder is excreted in urine [21, 22]. After the patient was referred to the Department of Gastroenterology due to hyperbilirubinemia, both the diagnostic tests and the liver function tests results showed the possible diagnosis of GS. Furthermore, his liver biopsy and WES results confirmed our assumption. Therefore, within several months after discontinuing LEV, the indirect bilirubin was still mild and showed intermittent elevation. Up to now, there have been, to our knowledge, no reports of abnormalities of bilirubin caused by LEV alone. For an epileptic patient with concurrent hyperbilirubinemia, timely diagnosis, treatment and periodical liver tests are necessary for choosing the most appropriate AEDs.

In conclusion, this case report serves to highlight that if a patient taking AEDs had recurrent hyperbilirubinemia and there was no improvement after taking the AEDs that involved nonhepatic metabolic pathways, the existence of GS should be suspected. Timely diagnosis and periodical liver tests hold important practical implications for the treatment of epilepsy concurrent with GS.

\section{Statement of Ethics}

Written informed consent was obtained from the patient.

\section{Disclosure Statement}

The authors declare that they have no conflicts of interest to disclose.

\section{Funding Sources}

No funding was assigned to this study. 


\section{Case Reports in Gastroenterology}

Case Rep Gastroenterol 2020;14:39-47

DOI: $10.1159 / 000504645$

(c) 2020 The Author(s). Published by S. Karger AG, Base www.karger.com/crg

Zhang et al.: Gilbert Syndrome Concurrent with Epilepsy

\section{Author Contributions}

Yaoyao Zhang: study concept and design, writing the first draft, acquisition/analysis/interpretation of data, the critical revision, study supervision.

Yongli Jiang: acquisition/analysis/interpretation of data, critical revision, study supervision.

Fang Yuan: acquisition/analysis/interpretation of data, critical revision, study supervision.

Changgeng Song: acquisition/analysis/interpretation of data, critical revision, study supervision.

Zhihan Zhao: acquisition/analysis/interpretation of data, critical revision, study supervision.

Wen Jiang: study concept and design, critical revision, study supervision.

\section{References}

1 Bosma PJ, Chowdhury JR, Bakker C, Gantla S, de Boer A, Oostra BA, et al. The genetic basis of the reduced expression of bilirubin UDP-glucuronosyltransferase 1 in Gilbert's syndrome. N Engl J Med. 1995 Nov;333(18):1171-5.

2 Radu P, Atsmon J. Gilbert's syndrome-clinical and pharmacological implications. Isr Med Assoc J. 2001 Aug;3(8):593-8.

3 Radoi VE, Ursu RI, Poenaru E, Arsene C, Bohiltea CL, Bohiltea R. Frequency of the UGT1A1*28 Polymorphism in a Romanian Cohort of Gilbert Syndrome Individuals. J Gastrointestin Liver Dis. 2017 Mar;26(1):25-8.

4 Scheffer IE, Berkovic S, Capovilla G, Connolly MB, French J, Guilhoto L, et al. ILAE classification of the epilepsies: Position paper of the ILAE Commission for Classification and Terminology. Epilepsia. 2017 Apr;58(4):512-21.

5 Powell LW, Hemingway E, Billing BH, Sherlock S. Idiopathic unconjugated hyperbilirubinemia (Gilbert's syndrome). A study of 42 families. N Engl J Med. 1967 Nov;277(21):1108-12.

6 Ehmer U, Kalthoff S, Fakundiny B, Pabst B, Freiberg N, Naumann R, et al. Gilbert syndrome redefined: a complex genetic haplotype influences the regulation of glucuronidation. Hepatology. 2012 Jun;55(6): 1912-21.

7 Hu ZY, Yu Q, Zhao YS. Dose-dependent association between UGT1A1*28 polymorphism and irinotecaninduced diarrhoea: a meta-analysis. Eur J Cancer. 2010 Jul;46(10):1856-65.

8 Cuperus FJ, Hafkamp AM, Hulzebos CV, Verkade HJ. Pharmacological therapies for unconjugated hyperbilirubinemia. Curr Pharm Des. 2009;15(25):2927-38.

9 Hirschfield GM, Alexander GJ. Gilbert's syndrome: an overview for clinical biochemists. Ann Clin Biochem. 2006 Sep;43(Pt 5):340-3.

10 Erlinger S, Arias IM, Dhumeaux D. Inherited disorders of bilirubin transport and conjugation: new insights into molecular mechanisms and consequences. Gastroenterology. 2014 Jun;146(7):1625-38.

11 Maruo Y, Nakahara S, Yanagi T, Nomura A, Mimura Y, Matsui K, et al. Genotype of UGT1A1 and phenotype correlation between Crigler-Najjar syndrome type II and Gilbert syndrome. J Gastroenterol Hepatol. 2016 Feb;31(2):403-8.

12 Schmidt D, Schachter SC. Drug treatment of epilepsy in adults. BMJ. 2014 Feb 28;348:g254.

13 Tomson T, Landmark CJ, Battino D. Antiepileptic drug treatment in pregnancy: changes in drug disposition and their clinical implications. Epilepsia. 2013 Mar;54(3):405-14.

14 Vajda FJ, Eadie MJ. The clinical pharmacology of traditional antiepileptic drugs. Epileptic Disord. 2014 Dec;16(4):395-408.

15 Rowland A, Elliot DJ, Williams JA, Mackenzie PI, Dickinson RG, Miners JO. In vitro characterization of lamotrigine N2-glucuronidation and the lamotrigine-valproic acid interaction. Drug Metab Dispos. 2006 Jun;34(6):1055-62.

16 Clarkson A, Choonara I. Surveillance for fatal suspected adverse drug reactions in the UK. Arch Dis Child. 2002 Dec;87(6):462-6. 


\section{Case Reports in Gastroenterology}

\begin{tabular}{l|l}
\hline Case Rep Gastroenterol 2020;14:39-47 \\
\hline DOI: 10.1159/000504645 & $\begin{array}{l}\text { @ 2020 The Author(s). Published by S. Karger AG, Basel } \\
\text { www.karger.com/crg }\end{array}$ \\
\hline
\end{tabular}

Zhang et al.: Gilbert Syndrome Concurrent with Epilepsy

17 Su-Yin AN, Tai WW, Olson KR. Lamotrigine-associated reversible severe hepatitis: a case report. J Med Toxicol. 2008 Dec;4(4):258-60.

18 Powell-Jackson PR, Tredger JM, Williams R. Hepatotoxicity to sodium valproate: a review. Gut. 1984 Jun;25(6):673-81.

19 Im SG, Yoo SH, Park YM, Lee SJ, Jang SK, Jeon DO, et al. Liver dysfunction induced by systemic hypersensitivity reaction to lamotrigine: case report. Clin Mol Hepatol. 2015 Jun;21(2):180-2.

20 Krähenbühl S, Brandner S, Kleinle S, Liechti S, Straumann D. Mitochondrial diseases represent a risk factor for valproate-induced fulminant liver failure. Liver. $2000 \mathrm{Jul}$;20(4):346-8.

21 Strolin Benedetti M, Whomsley R, Nicolas JM, Young C, Baltes E. Pharmacokinetics and metabolism of 14Clevetiracetam, a new antiepileptic agent, in healthy volunteers. Eur J Clin Pharmacol. 2003 Nov;59(8-9):62130.

22 Patsalos PN. Clinical pharmacokinetics of levetiracetam. Clin Pharmacokinet. 2004;43(11):707-24.

23 Bohan KH, Mansuri TF, Wilson NM. Anticonvulsant hypersensitivity syndrome: implications for pharmaceutical care. Pharmacotherapy. 2007 Oct;27(10):1425-39.

24 Berkovic SF, Knowlton RC, Leroy RF, Schiemann J, Falter U; Levetiracetam N01057 Study Group. Placebocontrolled study of levetiracetam in idiopathic generalized epilepsy. Neurology. 2007 Oct;69(18):1751-60.

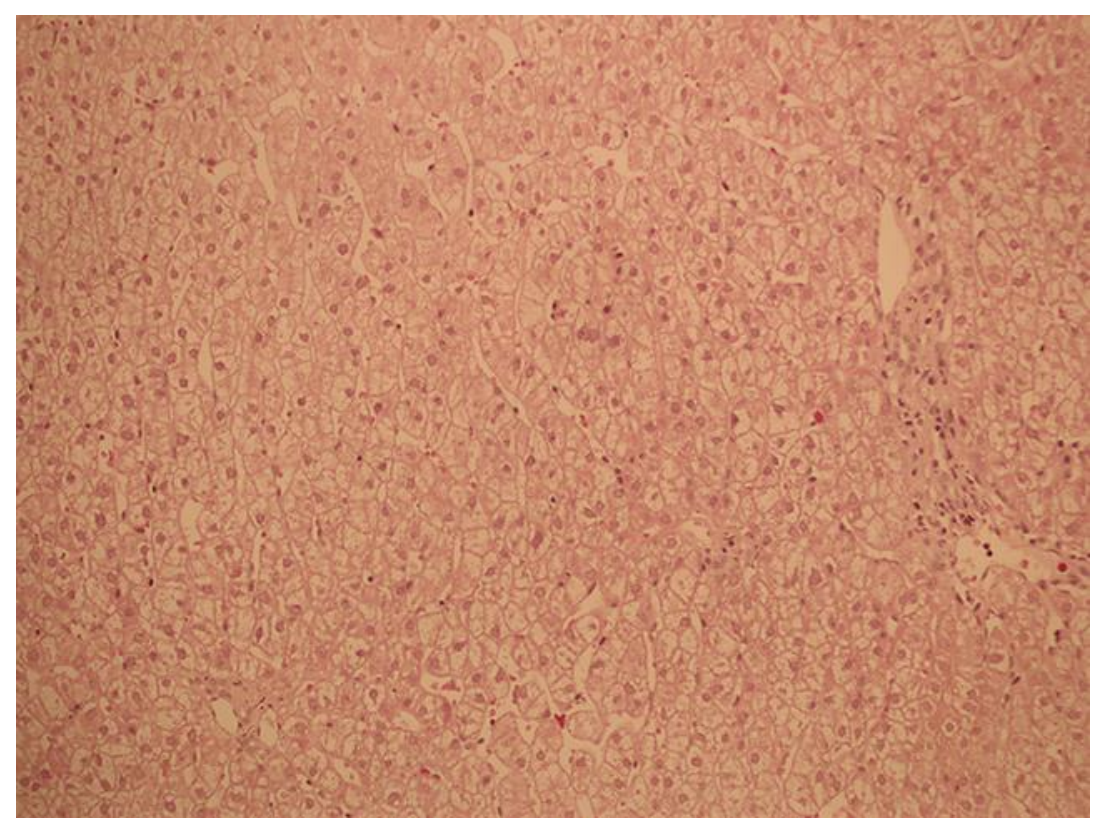

Fig. 1. In the pathological findings from the hepatocyte specimen, hematoxylin and eosin staining showed that hepatocytes are mildly edematous and there were only few eosinophils infiltrating in them $(\times 20)$. 


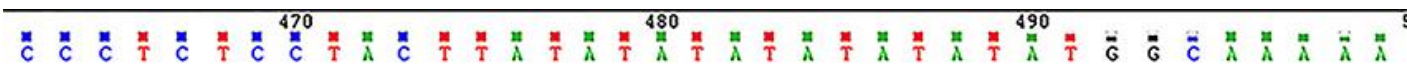

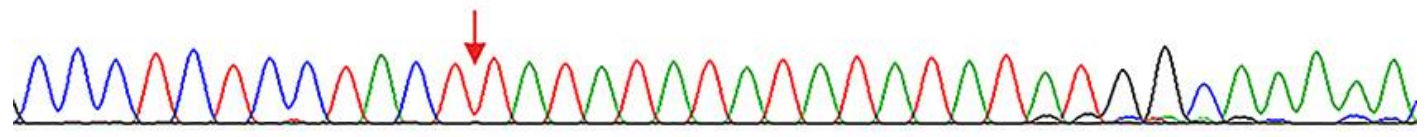

Fig. 2. Homozygous mutation (p. A(TA)6TAA ins TA) in the UGT1A1 promoter of GS pathogenic gene locus: chr2 234668880-234668881. 
 Gastroenterology}

\begin{tabular}{l|l}
\hline Case Rep Gastroenterol 2020;14:39-47 \\
\hline DOI: 10.1159/000504645 & $\begin{array}{l}\text { ○ 2020 The Author(s). Published by S. Karger AG, Basel } \\
\text { www.karger.com/crg }\end{array}$ \\
\hline
\end{tabular}

Zhang et al.: Gilbert Syndrome Concurrent with Epilepsy

Table 1. Time course of serum bilirubin when the patient was taking different AEDs under diverse daily doses

\begin{tabular}{lllllll}
\hline AEDs & Doses, g/day & DOE & $\begin{array}{l}\text { TBil } \\
(0-25 \mu \mathrm{mol} / \mathrm{L})\end{array}$ & $\begin{array}{l}\text { DBil } \\
(0-7 \mu \mathrm{mol} / \mathrm{L})\end{array}$ & $\begin{array}{l}\text { IDBil } \\
(0-18 \mu \mathrm{mol} / \mathrm{L})\end{array}$ \\
\hline VPA & 0.5 & Jun 2010 & 73.5 & 21.2 & 52.3 \\
\hline LTG & 0.075 & Aug 2010 & 71.4 & 20.0 & 51.4 \\
LTG & 0.05 & Apr 2011 & 34.2 & 12.5 & 21.7 & \\
\hline LEV & 0.75 & Jun 2011 & 69.4 & 13.9 & 55.5 & \\
LEV & 0.75 & Jul 2011 & 41.1 & 12.7 & 28.4 & $\mathrm{a}$ \\
LEV & 0.75 & Jul 2011 & 136.8 & 9.5 & 127.3 & $\mathrm{~b}$ \\
LEV & 0.75 & Jul 2011 & 23.4 & 8.2 & 15.2 & $\mathrm{c}$ \\
LEV & 1 & Aug 2011 & 60.5 & 16.3 & 44.2 & \\
LEV & 0.75 & Feb 2012 & 59.7 & 10.8 & 48.9 & \\
LEV & 0.75 & Aug 2012 & 62.9 & 13.3 & 49.6 & \\
LEV & 0.75 & Jan 2013 & 46.9 & 10.9 & 36.0 & \\
LEV & 0.75 & Sep 2013 & 76.8 & 13.7 & 63.1 & \\
LEV & 0.75 & Mar 2014 & 43.3 & 11.6 & 68.7 & \\
LEV & 0.75 & Oct 2014 & 75.6 & 7.4 & 36.8 & \\
LEV & 0.75 & Mar 2015 & 49.4 & 12.6 & 29.3 & \\
LEV & 0.5 & Mar 2016 & 39.8 & 10.5 & 33.2 \\
LEV & 0.25 & Apr 2017 & 45.9 & 12.7 & 33.4 \\
\hline Stopped & 0 & Nov 2017 & 50.9 & 17.5 & 17.5 \\
Stopped & 0 & Mar 2018 & 24.4 & 6.9 & 27.9 \\
Stopped & 0 & Aug 2018 & 39.1 & 11.2 & \\
Stopped & 0 & Mar 2019 & 31.9 & 10.1 & 21.8 \\
\hline
\end{tabular}

AEDs, antiepileptic drugs; VPA, valproic acid; LTG, lamotrigine; LEV, levetiracetam; DOE, date of examination; TBil, total bilirubin; DBil, direct bilirubin; IDBil, indirect bilirubin; a, the bilirubin results before caloric restriction test; $b$, the bilirubin results after the caloric restriction test; $c$, the bilirubin results after oral phenytoin sodium stimulation test (and the reference values are different: TBil: 3.4-20.5 $\mu \mathrm{mol} / \mathrm{L}$, DBil: 1.7-6.8 $\mu \mathrm{mol} / \mathrm{L}$, IDBil: 6.8-12.0 $\mu \mathrm{mol} / \mathrm{L})$. 